Based on short-term results, we can only speculate on the longevity of this new repair approach. However, placement of artificial primary chordae with polytetrafluoroethylene sutures has been associated with encouraging results in our experience. The excursion of the anterior mitral leaflet has not been limited by the STRING suture in the previous experimental setting ${ }^{5}$ or in our clinical observations. Long-term follow-up is needed to prove the clinical role of this new repair option for patients with IMR.

\section{References \\ 1. McGee EC, Gillinov AM, Blackstone EH, Rajeswaran J, Cohen G, Najam F, et al. Recurrent mitral regurgitation after annuloplasty for}

functional ischemic mitral regurgitation. J Thorac Cardiovasc Surg. 2004;128:916-24.

2. Calafiore AM, Di Mauro M, Gallina S, Di Giammarco G, Iaco AL, Teodori G, et al. Mitral valve surgery for chronic ischemic mitral regurgitation. Ann Thorac Surg. 2004;77:1989-97.

3. Kron IL, Green GR, Cope JT. Surgical relocation of the posterior papillary muscle in chronic ischemic mitral regurgitation. Ann Thorac Surg. 2002;74:600-1.

4. Tibayan FA, Rodriguez F, Zasio MK, Bailey L, Liang D, Daughters GT, et al. Geometric distortions of the mitral valvular-ventricular complex in chronic ischemic mitral regurgitation. Circulation. 2003;108(suppl II):II116-21.

5. Langer F, Rodriguez F, Ortiz S, Cheng A, Nguyen TC, Zasio MK, et al. Subvalvular repair: the key to repairing ischemic mitral regurgitation? Circulation. 2005;112(suppl I):I383-9.

\title{
An alternative technique for aortic root remodeling in patients with bicuspid aortic valve
}

\author{
Gino Gerosa, MD, ${ }^{a}$ Sara Pontarollo, MD, ${ }^{\text {b }}$ Sabino Iliceto, MD, and Francesca di Marco, MD, a Padua, Italy
}

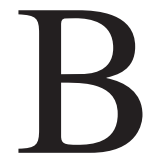

icuspid aortic valve (BAV) presents with an incidence of $0.5 \%$ to $2 \% .^{1}$ It is associated with abnormal dilation of the ascending aorta in approximately $10 \%$ of cases ${ }^{2}$ or more complex anomalies. ${ }^{3}$ The optimal surgical strategy for the management of ascending aortic dilation in the presence of BAV has not been identified.

We propose an alternate remodeling technique for ascending aortic dilation in patients with $\mathrm{BAV}$, which protects the patient from sinusal dilation, avoiding mobilization of the coronary sinuses.

At our institution, between November 1999 and December 2005, 21 consecutive adult patients (mean age, $55 \pm 15$ years; range, 31-75 years) with BAV with anteroposterior cusp orientation and indication for ascending aorta replacement, presented at the intraoperative observation with aortic root dilation involving the posterior noncoronary sinus.

At the time of transthoracic echocardiography, the mean diameter of the aortic root at the sinuses of Valsalva was $43 \pm 6 \mathrm{~mm}$,

From the Division of Cardiac Surgery, Department of Cardiac, Thoracic and Vascular Sciences, ${ }^{\mathrm{a}}$ and the Division of Cardiology, Department of Cardiac, Thoracic and Vascular Sciences, ${ }^{\text {b }}$ Padua University Medical School, Padua, Italy.

Received for publication July 14, 2006; accepted for publication Aug 8, 2006.

Address for reprints: Gino Gerosa, MD, Division of Cardiac Surgery, Department of Cardiac, Thoracic and Vascular Sciences, Padua University Medical School, Via Giustiniani 2, 35100 Padova, Italy (E-mail: gino.gerosa@unipd.it).

J Thorac Cardiovasc Surg 2007;133:249-50

$0022-5223 / \$ 32.00$

Copyright $\odot 2007$ by The American Association for Thoracic Surgery doi:10.1016/j.jtcvs.2006.08.063 and the mean ascending aortic diameter was $50 \pm 7 \mathrm{~mm}$. In $52 \%$ of cases, the aortic valve was purely regurgitant, whereas in $19 \%$ it was stenotic.

In all cases, at intraoperative inspection, the aortic dilation appeared to be confined to the noncoronary sinus, without coronary ostia displacement (Figure 1). The aneurysmal portion of the aorta was excised. Proximally, the excision was extended into the noncoronary sinus. The sinus wall was removed, leaving a few millimeters of aortic wall. A Teflon strip (DuPont, Wilmington, Del) and the proximal end of the vascular graft were molded according to the removed aortic wall in correspondence with the resected sinus (Figure 2, A). The proximal end of the graft was anastomosed to the aortic wall with continuous 4-0 polypropylene sutures, and the Teflon felt was used to reinforce the proximal anastomosis. (Figure 2, B).

The distal anastomosis was performed by means of continuous sutures and Teflon felt reinforcement.

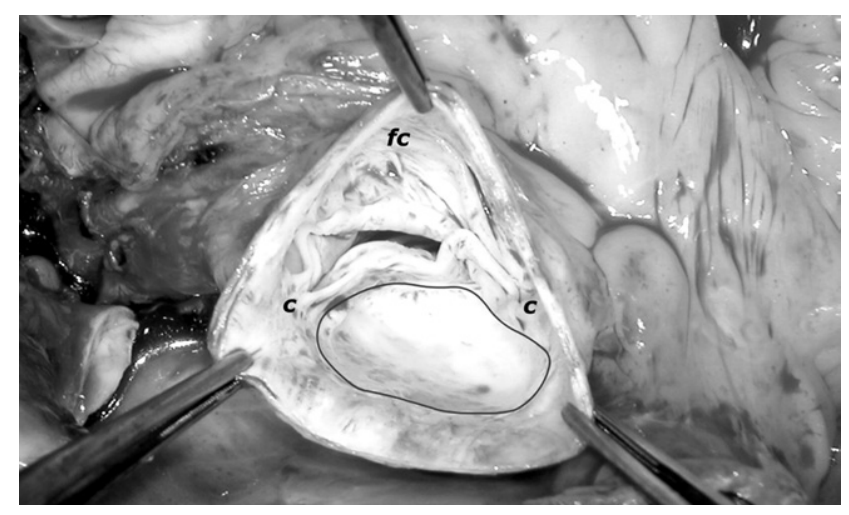

Figure 1. Intraoperative view. The isolated expansion of the posterior noncoronary sinus is evident. $c$, True commissures; $f c$, false commissure. 

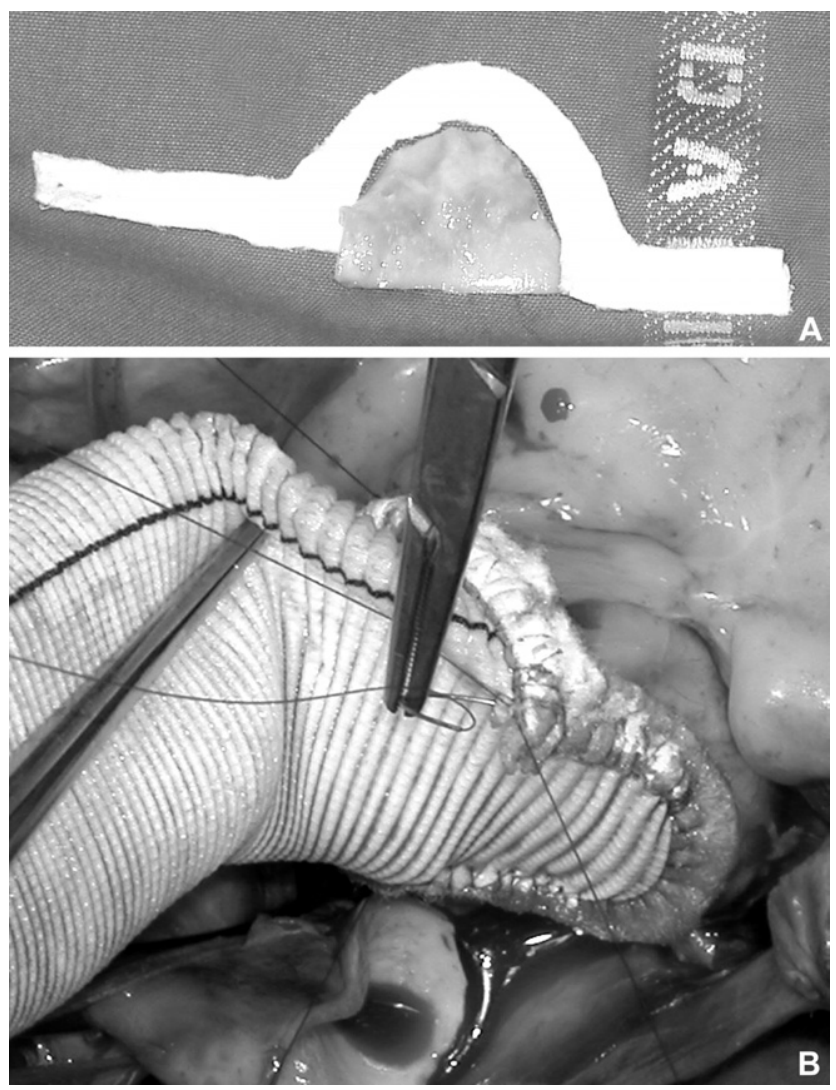

Figure 2. Top, A Teflon felt, which will be used to reinforce the proximal anastomosis, is molded on the synthetic graft profile. Bottom, Final view of the reconstructed aortic root.

In $15(71 \%)$ patients the aortic valve was replaced. In 1 patient the valve was suitable for a debridement procedure.

There were no in-hospital deaths, and all patients were discharged at home in good clinical status after a mean hospital stay of $8 \pm 4$ days. At the predischarge echocardiography, no abnormal dilation of the aortic root was evidenced.

At a mean follow-up time of $15 \pm 19$ months (median time, 7 months; range, 1-73 months), there were no late deaths, and patients are in good functional status. There were no reoperations for aneurysm recurrence or dissection. At the follow-up echocardiographic evaluation, aortic root diameter at the midsinus was 35 $\pm 2 \mathrm{~mm}$.

The aortic root is a complex anatomic structure composed of aortic cusps and commissures, aortic sinuses, and coronary artery origin. A dilative process of the ascending aorta might be localized or might involve the entire aortic root, leading to a diffuse compromise of all the root components. Subsequently, the surgical treatment comprehends a wide spectrum of options, ranging from isolated replacement of the diseased segment to a Bentall procedure.

Aortic dilation can accompany $\mathrm{BAV},{ }^{2}$ and the incidence of aortic dissection, aneurysm, and rupture is increased in patients with $\mathrm{BAV}^{4}$ : for these reasons, an aggressive surgical approach on the ascending aorta is recommended. The involvement of the sinusal aortic portion often is not symmetric. In particular, the noncoronary sinus, which in human subjects is basically larger than the coronary sinuses, usually dilates first, ${ }^{5}$ as we can confirm with our experience. Subsequently, an isolated enlargement of the noncoronary sinus can be found in patients undergoing replacement of the ascending aorta.

We propose this alternative approach, which lies in the middle of the spectrum of surgical options for the management of ascending aortic dilation. We believe that selective noncoronary sinus replacement offers several advantages. It allows correction of the sinusal aortic deformation, replacing selectively the dilated portion and reducing wall stress while the patient is not exposed to the risks related to mobilization and reimplantation of the coronary ostia. It better preserves aortic root flexibility and physiologic flow compared with the composite approach. The excision of the noncoronary sinus reduces the risk of future aortic dissection, with the noncoronary sinus often being the primary sinus involved in a dissection.

The proposed technique is feasible both in patients requiring aortic valve replacement and in patients necessitating only correction of an aortic aneurysm. It is less technically demanding and time-consuming compared with a valve-sparing replacement procedure.

We are convinced that the selective replacement of the noncoronary sinus in combination with ascending aorta replacement properly responds to the specific aortic root geometric conformation and root dynamics characterizing BAV. We believe it could also be prophylaptically adopted to stabilize the aortic root in patients with BAV with a dilated aorta not yet involving the sinusal segment of the aortic root.

We thank Mr Nicola Paccagnella for setting the figures.

\section{References}

1. Roberts WC. The congenitally bicuspid aortic valve. A study of 85 autopsy cases. Am J Cardiol. 1970;26:72-83.

2. Bauer M, Pasic M, Schaffarzyk R, Siniawsky H, Knollmann F, Meyer R, et al. Reduction aortoplasty for dilatation of the ascending aorta in patients with bicuspid aortic valve. Ann Thorac Surg. 2002;73:720-4

3. di Marco F, Giordan M, Pittarello D, Gerosa G. Moray mouth heartGerosa tetralogy. Int J Cardiol. 2005;113:274-5.

4. Fedak PW, Verma S, David TE, Leasle RL, Weisel RD, Butani J. Clinical and pathophysiological implications of a bicuspid aortic valve. Circulation. 2002;106:900-4.

5. Lehy RG, Schmidtke C, Sievers H-H, Yacoub M. Opening and closure characteristics of the aortic valve after different types of valve-preserving surgery. Circulation. 1999;100:2153-60. 